\title{
COMBINED NUMERICAL-EXPERIMENTAL FRAMEWORK FOR STRAIN BASED DESIGN AND FLAW ASSESSMENT OF GIRTH WELDS
}

\author{
S. Hertelé ${ }^{1}$, R. Denys ${ }^{1}$, K. Van Minnebruggen ${ }^{1}$, M. Verstraete ${ }^{1}$ and W. De Waele ${ }^{1}$ \\ ${ }^{1}$ Ghent University, Laboratory Soete, Belgium
}

\begin{abstract}
An increasing number of transmission pipelines have to be installed and operated in harsh conditions, due to the diminishing reserves of exploited fossil fuel sources. Under certain environment related circumstances, longitudinal plastic strains are imposed. When tensile, these may induce failure in girth welds in conjunction with the inevitable presence of weld defects. A large number of factors related to environment, material, geometry and operating conditions influence the tensile strain capacity and, hence, the acceptability of girth weld flaws. Therefore, a project specific development of guidelines in this strain based context is recommended. This paper provides systematic frameworks on (a) how to design pipelines under strain based conditions, and (b) how to assess girth weld flaws that were detected using non destructive testing. Attention is given to several technical and economical aspects related to the selection and qualification of pipe and weld metals, and to the evaluation of flaw acceptability. Both frameworks comprise a combined experimental-numerical approach, collecting project development reports from literature with research carried out at Soete Laboratory. Concretely, four in-house realizations are adopted: the UGent equation for strain capacity, the curved wide plate tension test, the UGent stress-strain equation and a finite element model of full scale pressurized pipe tension testing. The proposed frameworks aim to facilitate in performing thorough and economically justifiable strain based design and assessment processes.
\end{abstract}

Keywords: girth weld; weld flaw; strain based design; strain based assessment; project approach

\section{INTRODUCTION}

The availability of fossil fuel reserves decreases [1]. As a consequence, transport pipelines are installed and operated in increasingly challenging circumstances. Such pipelines may suffer from plastic strains that are being imposed under (partially) displacement controlled loading. Their structural integrity is to be judged in a strain based context, which considers strain as an evaluation quantity rather than stress. In this respect, the tensile strain capacity of the structure (i.e. the tensile strain level corresponding with failure of the structure) should exceed the strain demand (i.e. the strain level resulting from the imposed conditions).

The strain based evaluation of pipelines under displacement controlled loading can be considered at two stages. First, devoted choices are to be taken during the design stage, prior to the construction of the pipeline. This aspect is referred to as a 'strain based design'. Second, the girth welds that connect pipe sections potentially contain weld flaws. A fracture mechanics based evaluation of their acceptability requires a method for strain based flaw assessment.

To date, there are no standardized procedures for the strain based design of pipelines and their girth welds. Further, strain based assessment procedures for girth weld flaws have been developed during the last decade, but all of them show limitations with respect to conservativeness, sensitivity to inputs and/or the coverage of key influence parameters [2]. As a result, previous and current strain based designs and flaw assessments have mostly been treated on a project specific basis.

This paper focuses on both strain based design and strain based flaw assessment, for the specific case of tensile loaded (and pressurized) pipelines and assuming materials with sufficient toughness to avoid brittle fracture. To promote the systematic execution of project specific designs and flaw assessments under strain based conditions, frameworks are presented for both aspects. These frameworks are to a great extent in correspondence with earlier proposed strategies. Some steps, however, are enabled by the use of in-house developed analytical, experimental and numerical tools.

The paper is structured as follows. Section 2 covers the design of a pipeline in a strain based context. Section 3 is devoted to the strain based assessment of girth weld flaws. Conclusions are drawn in section 4.

\section{FRAMEWORK FOR STRAIN-BASED PIPE AND GIRTH WELD DESIGN}

The proposed framework is depicted in Figure 1 and discussed step by step below. 


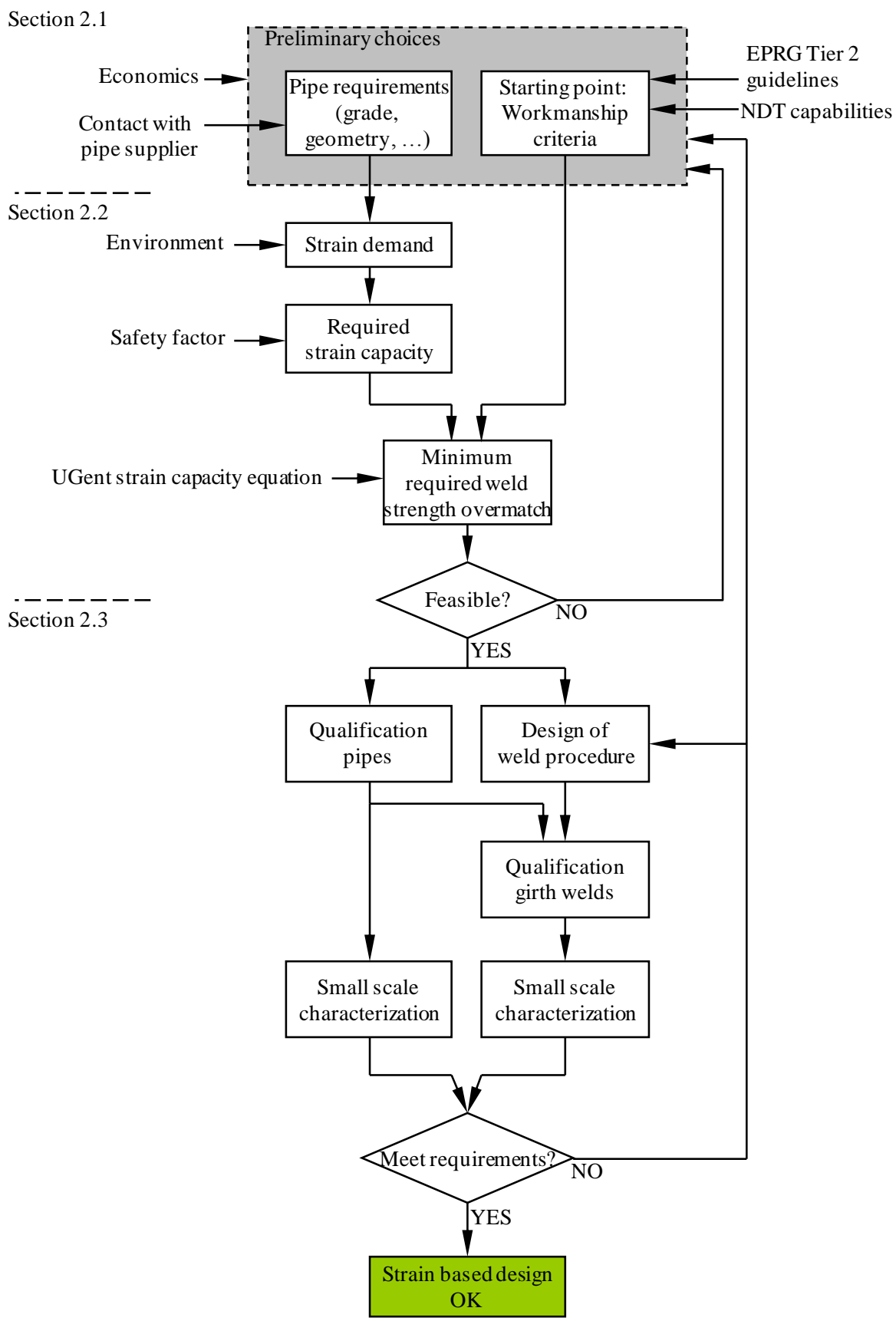

Figure 1. Proposed framework for strain based design under tensile deformation.

\subsection{Preliminary choices}

Every design starts with a set of preliminary choices. In this particular case, these choices mostly follow from the pressure design equation which translates that the operational pressure should not exceed the pipe's burst pressure. This design criterion is typically in the form of Eq. (1) (adopted from CSA Z662 [3]), which gives the following maximum allowable operational pressure $p_{\max }(\mathrm{MPa})$ in a straight pipe:

$$
p_{\text {max }}=\operatorname{SMYS} \frac{2 t}{D_{o}} C_{F} C_{L} C_{J} C_{T}
$$

with SMYS (MPa) the specified minimum yield strength of the line pipe steel grade, $t(\mathrm{~mm})$ the pipe wall thickness and $D_{o}(\mathrm{~mm})$ its outer diameter. The CSA Z662 equation adopts dimensionless safety factors $C_{F}$, $C_{L}, C_{J}$ and $C_{T}$, respectively for design, location (vicinity to human activity), pipe type (e.g. UOE), and temperature.

The pressure design equation is closely related to major economical aspects of the pipeline design [4]. According to Eq. (1), an increased strength grade (i.e. SMYS) allows for a higher operational pressure and/or a lower wall thickness, both of which result in considerable cost savings at many levels of the 
project. For instance, a higher operational pressure may allow for a smaller diameter pipe, whereas a reduction of wall thickness evidently leads to material savings. In [5], it was calculated for a specific project that upgrading the steel from API 5L grade X70 $($ SMYS $=485 \mathrm{MPa})$ to X100 $(\mathrm{SMYS}=690 \mathrm{MPa})$ would result in $10 \%$ savings on the total cost.

\subsection{Requirements for strain based design}

Assuming a certain pipe design (i.e. material characteristics of line pipe steel, wall thickness, diameter), its interactions with environmental conditions (e.g. pipe-soil interactions for onshore buried pipelines [6, 7]) can be evaluated. This allows for an estimation of strain demand. Next, applying a safety factor on this strain level leads to a minimum required strain capacity. This safety factor may take into account several environmentally governed aspects related to

- frequency: What is the possibility of occurrence of the considered strain demand mechanism(s)?

- severity: What are the potential consequences of a pipeline failure to people and/or ecosystems?

- detectability: Can severe strains be monitored (e.g. by means of GPS equipped pigging [8]) and acted upon in time?

Following the estimation of minimum required strain capacity, workmanship criteria and non destructive testing (NDT) capabilities are adopted for a quantification of allowable and identifiable flaw sizes. To the former's respect, the allowable flaw sizes described in the European Pipeline Research Group (EPRG) Tier 2 'guidelines for the assessment of defects in transmission pipeline girth welds' [9] are proposed. These guidelines provide sufficient conditions for the achievement of remote yielding prior to girth weld failure. In this respect, they are somewhat closer related to strain based design conditions than other workmanship criteria, which rather focus on a linear elastic response.

After flaw size criteria have been decided upon, and ensuring non-brittle fracture behaviour (translated in terms of $60 \mathrm{~J}$ minimum, $80 \mathrm{~J}$ average required $\mathrm{CVN}$ according to [10]), the strain capacity of a flawed girth weldment $e_{\max }(-)$ is to a great extent governed by the actual stress-strain properties of the involved metals. This is reflected in the so-called 'UGent strain capacity equation', given by [10]:

$$
e_{\text {max }}=P_{c}\left[\frac{Y / T_{B M}+1}{1-Y / T_{B M}} \cdot \frac{0.5-C_{m} e_{m, B M} M_{F S}}{C_{d}} \gamma+C_{m} e_{m, B M} M_{F S}\right]
$$

with $Y / T_{B M}(-)$ and $e_{m, B M}(-)$ the yield-to-tensile ratio and uniform elongation of the base metal (i.e. the line pipe steel), and $M_{F S}(-)$ the flow stress mismatch of the weld metal, defined as the ratio between the flow stresses of weld and base metal. Hereby, flow stress represents the average of yield and ultimate tensile strength. Further, the flaw is represented by its area, relative to the unflawed cross section, $\gamma(-) . C_{m}(-)$ and $C_{d}(-)$ are correction factors that were tuned against experimental results in order to obtain conservative predictions. These results were obtained from 480 Curved Wide Plate (CWP) tension tests performed at Soete Laboratory, Ghent University (covering API $5 \mathrm{~L}$ grades up to X80). Since these tests represent uniaxial tension conditions, a correction factor $P_{c}(-)$ has been introduced to account for the detrimental effect of biaxiality introduced by combined axial tension and internal pressure [11].

Eq. (2) predicts a linear relation between strain capacity $e_{\max }$ and weld flow stress mismatch $M_{F S}$ (considering that all other inputs remain constant), higher levels of mismatch corresponding with an increased strain capacity. In the proposed framework, this relation is used to estimate the minimum required $M_{F S}$, given assumed line pipe steel properties $Y / T_{B M}$ and $e_{m, B M}$, and workmanship defect sizes.

The resulting design choices should be judged for feasibility and, if necessary, adapted in an iterative manner. In particular, the abovementioned economical incentive for increasing the pipe strength grade is counteracted by the technical boundaries of current steelmaking and welding practice. Higher grade line pipe steels tend to have less strain hardening (reflected in a higher yield-to-tensile ratio $Y / T_{B M}$ ), less ductility (reflected in a lower uniform elongation $e_{m, B M}$ ) and may be sensitive to strain aging [12]. Also, the achievement of girth welds with adequate toughness and strength properties (translated to a sufficient flow stress mismatch $M_{F S}$ ) is more challenging for a stronger line pipe steel. This feasibility judgement requires material expertise and clear communication between all involved parties. For instance, the ability to achieve sufficient line pipe steel properties is to be discussed with the involved pipe manufacturer [13]. As a result, economical concessions may have to be made, for instance by choosing line pipe steel of a reduced strength grade.

\subsection{Qualification of materials}

After the feasibility judgement, qualification pipes are to be provided for extensive testing and for the creation of qualification girth welds. The pipes and welds should be representative to in-the-field conditions (e.g. pipes are to be coated or should have undergone a similar thermal cycle as applied during coating). 
Both shall be investigated for their ability to meet the required mechanical properties (strength, ductility, toughness). If unsatisfactory, adaptations may be made to the pipe design and/or to the weld procedure. The result is a final design with an experimentally proven fulfilment of all material requirements.

\section{$3 \quad$ FRAMEWORK FOR STRAIN-BASED ASSESSMENT OF GIRTH WELD FLAWS}

Considering that the pipes and girth welds meet their required mechanical properties, Eq. (2) ensures that workmanship criteria adopted at the strain based design stage (Figure 1) are conservative under the project specific circumstances. Flaws beyond workmanship are potentially unsafe. Their integrity may be investigated in a strain based engineering critical assessment, aiming to reduce the number of unnecessary weld repairs. The proposed framework is depicted in Figure 2 and discussed step by step below.

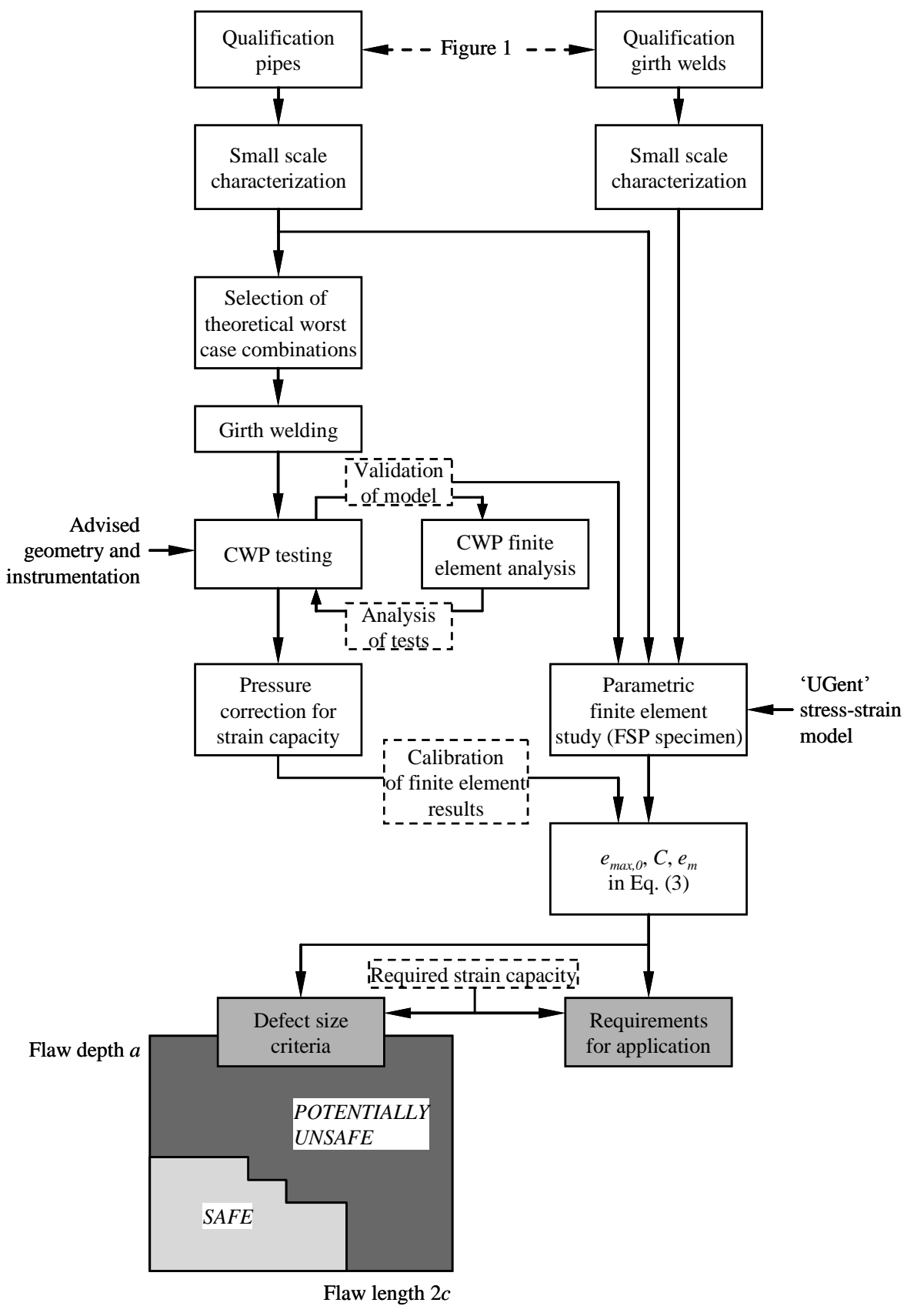

Figure 2. Proposed framework for strain based flaw assessment under tensile deformation.

Starting from the small scale characterization of qualification pipes (Figure 1), potential worst case pipe combinations (with respect to strain capacity) are selected and girth welded according to the weld 
procedure adopted in the project. This selection is based on stress-strain properties and requires engineering considerations, which should take into account at least the following cases:

- a weldment that connects pipes with unfavourable mechanical properties for strain based applications, e.g. high $Y / T$-ratio, low uniform elongation (see Eq. (2) and [14]).

- two pipes at the upper end of their specified strength range. The girth weld that connects these pipes may be critical due to the increased challenge to achieve the required weld strength mismatch, compared with a girth weld that connect pipes with a lower strength. Note that these pipes additionally tend to be more critical in terms of $Y / T$ and uniform elongation [15], which relates to the first case above.

- $\quad$ one pipe at the upper end and one pipe at the lower end of their strength range. This combination results in strongly heterogeneous strain distributions near the weld. Strains tend to concentrate in the weakest pipe. Such concentration is potentially detrimental to strain capacity [16].

From the obtained girth weldments, CWP specimens are extracted and tested at the project specific design temperature. Advice with respect to specimen geometry, instrumentation and test protocol is provided in [17]. As a specific advantage to full scale (pressurized) pipe (FSP) testing, multiple CWP specimens can be sampled from one girth weldment. This allows to investigate different flaw sizes / flaw locations in the same girth weld. Hence, flaw sizes can be sequentially chosen on the basis of previously obtained results with in the same weld (i.e. within similar materials), aiming at the project specific required strain capacity. Note that the uniaxial nature of CWP testing implies a proper estimation of the pressure correction factor $P_{c}$ for the strain capacity aimed at (Eq. (2)).

The collection of CWP test results gives a good first indication of (non-)allowable flaw sizes. Further support for the development of flaw assessment rules can be obtained through finite element analysis. An in-house developed Python script generates models of both CWP tests (Figure 3) and, similarly, full (pressurized) pipe tension tests [11]. Full details of the modelling approach are provided in [18]. Worth mentioning is that the creation, analysis and post-processing of models is fully parametric, and therefore highly suited for systematic studies that involve a substantial amount of simulations.

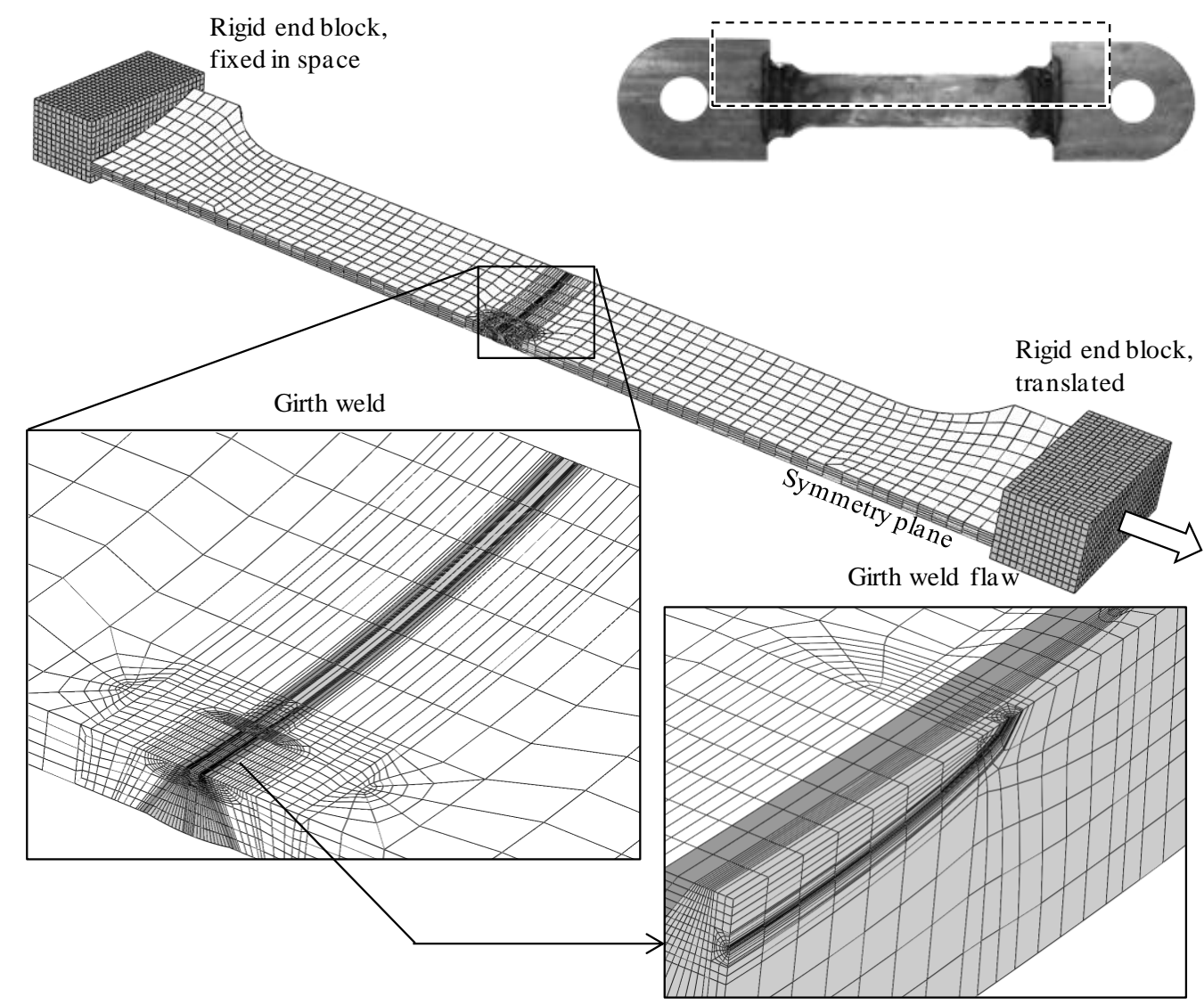

Figure 3. Finite element model of a CWP specimen. 
In the proposed framework, finite element analysis is used at two stages. First, confidence in the outcome of the model is gained by validating it against (a selection of) the experimental CWP results priorly obtained. If successful, this validation additionally provides an improved interpretation of the experimental data (e.g. estimation of ductile crack extension during the tests, and the related importance of the tearing resistance of the material that surrounds the flaw). Second, a parametric study covering different but representative material combinations, geometries and boundary conditions is performed. Full scale pressurized pipes are chosen for in this study. In particular, flaw dimensions are varied within chosen ranges of interest. Potential worst case material combinations as discussed above should deserve consideration. Statistical techniques may be applied to reduce the number of required finite element simulations. If desired, material properties can be parametrically modelled using the 'UGent' stress-strain model [19]. This model has two strain hardening stages, each independently characterized by a different strain hardening exponent (Figure 4). Previous work has shown that, in contrast with the more conventional Ramberg-Osgood model, the 'UGent' model is capable to accurately describe the full strain hardening behaviour up to necking of line pipe steels (provided there is no discontinuous yielding) [20]. Indeed, above a $Y / T$-ratio threshold of 0.80 , these steels tend to show two strain hardening stages as described by the 'UGent' stress-strain model. Recent research indicates that the same applies for girth weld material.

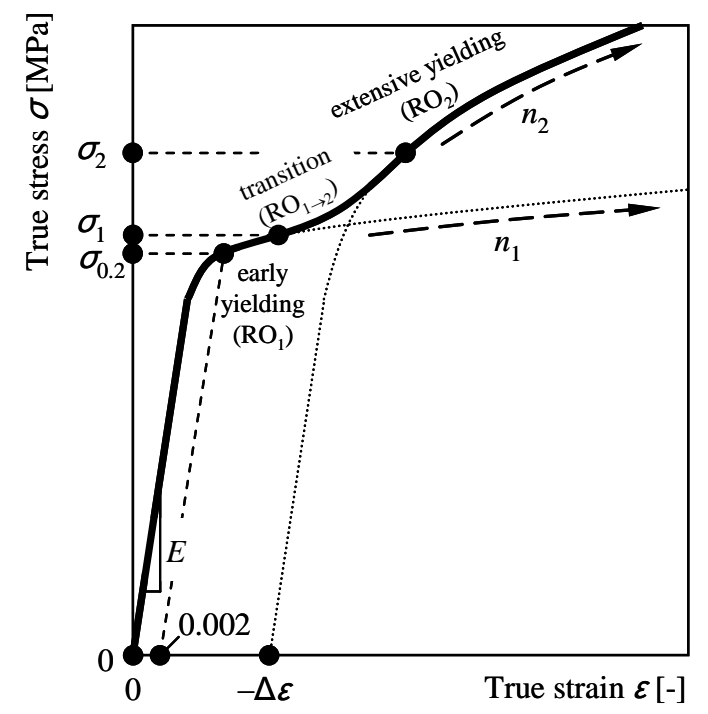

Figure 4. Graphical representation of the 'UGent' stress-strain model for line pipe steels [19].

The collection of finite element results allows to design a project-specific equation for strain capacity, similar to (but less conservative than) Eq. (2). This equation can be developed according to the following analytical framework, based on flow stress mismatch:

$$
e_{\max }=\min \left(e_{\max , 0}+100 C\left(M_{F S}-1\right), e_{\max , G S C}\right)
$$

where $e_{\max , 0}$ is the strain capacity for an evenmatching girth weld, $C$ is a sensitivity factor for weld strength mismatch, and $e_{\max , G S C}$ is an upper bound strain capacity. Numerical results reported in [21] have indicated that Eq. (3) adequately reflects effects of weld strength mismatch, both in cases of failure at the weld (left argument of the minimum) and failure at one of the pipes (right argument of the minimum). Further confidence in the use of Eq. (3) is given by its analytical similarity with Eq. (2), which is supported by a vast amount of experimental data.

The parametric study allows to tabulate worst case parameters $\left(e_{m a x, 0}, C, e_{m}\right)$ as a function of flaw dimensions. These parameters can be 'calibrated' by pressure corrected experimental CWP strain capacities to account for modelling assumptions. This technique has proved useful (and even necessary) for the modification of finite element analysis based strain capacity equations, developed by the ExxonMobil Upstream Research Company [22].

Finally, the obtained results are translated into concrete defect size criteria (allowable flaw length versus flaw depth, Figure 2 - bottom) to meet the strain capacity required according to Figure 1 . These criteria may involve a set of requirements for application (e.g. maximum allowable weld misalignment, minimum required tearing resistance of weld and/or heat-affected zone metal). As mentioned above, these criteria are far from generic given their dependence on project specific parameters such as strain demand, temperature, weld procedure and many more. Hence, the results should not readily be transferred to other projects involving different conditions. 


\section{CONCLUSIONS}

This paper has presented project specific guidelines for both the strain based design and strain based flaw assessment of pipeline girth weldments in challenging environments. These guidelines are confined to nonbrittle girth welds in pipes under axial tension. First, the following can be concluded with respect to strain based design aspects:

- $\quad$ Strain based pipeline design is a trade-off between the economical incentive of adopting higher strength line pipe steel and the related challenges with respect to achieving a required strain capacity level. These challenges apply to both line pipe steel (strain hardening, ductility and toughness) and girth weld (weld strength overmatch and toughness).

- The core of the proposed framework is an iterative application of the conservative 'UGent' strain capacity equation. The evaluated flaw sizes follow from the EPRG Tier 2 guidelines [9] and consider limitations of non-destructive testing.

- Extensive testing of both qualification pipes and qualification girth welds is essential to the soundness of the resulting design choices and the documentation of the project.

Second, a flaw assessment framework has the aim of reducing the number of unnecessary weld repairs due to overly conservative workmanship criteria. Major points of the proposed framework are given below.

- The development of flaw assessment criteria involves both experimental testing and numerical simulations. To achieve safe guidelines, potential (and realistic) worst case weldments should be considered for both. This requires engineering judgement based on the small scale characterization of the qualification material mentioned in the design framework.

- $\quad$ Curved wide plate tension testing allows for the sampling of multiple specimens per girth weld, and is less expensive than full scale pressurized pipe tension testing. A pressure correction factor is required to transfer the obtained strain capacity to the realistic situation, characterized by a combined internal pressure and tensile deformation.

- The finite element study considers girth welds in both CWP and full scale pressurized pipes. First, the model is validated on the basis of the experimental CWP tests. Then, full scale pipes are simulated to obtain allowable flaw sizes. The numerical results are calibrated on the basis of the pressure corrected experimental CWP results.

\section{ACKNOWLEDGEMENTS}

The authors would like to acknowledge the financial support of the FWO - Vlaanderen (Research Foundation - Flanders; grant nrs. 1.1.880.09.N.00 and 1.1.880.11.N.01) and the BOF (Special Research Fund - Ghent University; grant nr. BOF12/PDO/049).

\section{REFERENCES}

[1] Asif, M., Muneer, T., Energy Supply, its Demand and Security Issues for Developed and Emerging Economies, Renewable \& Sustainable Energy Reviews, 11(7), 1388-1413, 2007.

[2] Hertelé, S., Coupled Experimental-Numerical Framework for the Assessment of Strain Capacity of Flawed Girth Welds in Pipelines, PhD dissertation, Ghent University, 2012.

[3] CSA Z662, Oil \& Gas Pipeline Systems, Canadian Standards Association, 2007.

[4] Petersen, C.W., Corbett, K.T., Fairchild, D.P., Papka, S., Macia, M.L., Improving Long-distance Gas Transmission Economics: X120 Development Overview, Proceedings of the $4^{\text {th }}$ International Conference on Pipeline Technology, 1, 3-29, Ostend, Belgium, 2004.

[5] Glover, A., Rothwell, B., Yield Strength and Plasticity of High Strength Pipelines, Proceedings of the $4^{\text {th }}$ International Conference on Pipeline Technology, 1, 65-79, Ostend, Belgium, 2004.

[6] Kan, W.C., Weir, M., Zhang, M.M., Lillig, D.B., Barbas, S.T., Macia, M.L., Biery, N.E., Strain-based Pipelines: Design Consideration Overview, Proceedings of the $18^{\text {th }}$ International Offshore and Polar Engineering Conference, 174-181, Vancouver, BC, Canada, 2008.

[7] Arslan, H., Hamilton, J., Suvrat, L., Minnaar, K., Albrecht, B., Cook, M.F., Wong, P., Strain Demand Estimation for Pipelines in Challenging Arctic and Seismically Active Regions, Proceedings of the $8^{\text {th }}$ International Pipelone Conference, Calgary, Alberta, Canada, 2010.

[8] Pederson, I., Sen, M., Bidwell, A., Yoosef-Ghodsi, N., Enbridge Northern Pipeline: 25 Years of Operations, Successes and Challenges, Proceedings of the $8^{\text {th }}$ International Pipeline Conference, Calgary, Alberta, Canada, 2010. 
[9] Denys, R., Andrews, R., Zarea, M., Knauf, G., EPRG Tier 2 Guidelines for the Assessment of Defects in Transmission Pipeline Girth Welds, Proceedings of the 8th International Pipeline Conference, Calgary, Alberta, Canada, 2010.

[10]Denys, R., Hertelé, S., Verstraete, M., De Waele, W., Strain Capacity Prediction for Strain-based Pipeline Designs, Proceedings of the Internal Workshop on Welding of High Strength Pipeline Steels, Araxá, Brazil, 2011.

[11] Verstraete, M., De Waele, W., Denys, R., Hertelé, S., Pressure Correction Factor for Strain Capacity Predictions Based on Curved Wide Plate Testing, Proceedings of the 9th International Pipeline Conference, Calgary, Alberta, Canada, 2012.

[12] Hara, T., Shinohara, Y., Terada, Y., Asahi, H., Doi, N., Development of High-deformable High-strength Line Pipe Suitable for Strain-based Design, Proceedings of the 5th International Conference on Pipeline Technology, Ostend, Belgium, 2009.

[13] Macia, M.L., Kibey, S., Arslan, H., Bardi, F., Ford, S.J., Kan, W.C., Cook, M.F., Newbury, B., Approaches to Qualify Strain-based Designed Pipelines, Proceedings of the 8th International Pipeline Conference, Calgary, Alberta, Canada, 2010.

[14]Denys, R., Hertelé, S., Verstraete, M., Strain Capacity of Weak and Strong Girth Welds in Axially Loaded Pipelines, Proceedings of the International Pipeline Technology Conference, Beijing, China, 2010.

[15]Denys, R., Hertelé, S., De Waele, W., Lefevre, A., Estimate of Y/T Ratio and Uniform Elongation Capacity of Pipeline Steels from Yield Strength, Proceedings of the 5th International Conference on Pipeline Technology, Ostend, Belgium, 2009.

[16] Hertelé, S., De Waele, W., O'Dowd, N.P., Verstraete, M., Van Minnebruggen, K., Denys, R., Effects of Pipe Steel Heterogeneity on the Tensile Strain Capacity of a Flawed Pipeline Girth Weld, Engineering Fracture Mechanics, to be submitted.

[17]Denys, R., Lefevre, A., UGent Guidelines for Curved Wide Plate Testing, Proceedings of the 5th International Conference on Pipeline Technology, Ostend, Belgium, 2009.

[18] Hertelé, S., De Waele, W., Denys, R., Verstraete, M., Van Wittenberghe, J., Parametric Finite Element Model for Large Scale Tension Tests on Flawed Pipeline Girth Welds, Advances in Engineering Software, 47(1), 24-34, 2012.

[19] Hertelé, S., De Waele, W., Denys, R., A Generic Stress-Strain Model for Metallic Materials with Twostage Strain Hardening Behaviour, International Journal of Non-Linear Mechanics, 46(3), 519-531, 2011.

[20] Hertelé, S., De Waele, W., Denys, R., Verstraete, M., Full-range Stress-Strain Behaviour of Contemporary Pipeline Steels: Part I. Model Description, International Journal of Pressure Vessels and Piping, 92, 34-40, 2012.

[21] Hertelé, S., De Waele, W., Denys, R., Verstraete, M., Van Minnebruggen, K., Horn, A., Weld Strength Mismatch in Strain Based Flaw Assessment: Which Definition to Use?, Proceedings of the ASME 2012 Pressure Vessels and Piping Conference, Toronto, Canada, 2012.

[22] Fairchild, D.P., Macia, M.L., Kibey, S., Wang, X., Krishnan, V.R., Bardi, F., Tang, H., Cheng, W., A Multi-tiered Procedure for Engineering Critical Assessment of Strain-Based Pipelines, Proceedings of the 21st International Offshore and Polar Engineering Conference, 698-705, Maui, Hawaii, USA, 2011. 